\title{
Valores de nitrito e TBARS durante o processamento e armazenamento da paleta suína curada, maturada e fermentada.
}

\author{
Values of nitrite and TBARS along the process and storage of cured, ripened and fermented pig shoulders
}

\author{
Nelcindo Nascimento Terra ${ }^{1 *}$ Alexandre José Cichoski ${ }^{2}$ Renato João Sossela de Freitas ${ }^{3}$
}

RESUMO

Paletas suínas desossadas pesando em média $1,6 \mathrm{~kg}$ receberam injeção de salmoura contendo Staphylococcus xylosus. Permaneceram 30 dias em câmara de maturação em duas faixas de temperatura diferentes $\left(2^{\circ} \mathrm{C}\right.$ a $8^{\circ} \mathrm{C}$ e de $4^{\circ} \mathrm{C}$ a $9^{\circ} \mathrm{C}$ ), sendo posteriormente armazenadas durante 120 dias, nas temperaturas de $10^{\circ} \mathrm{C}$ e $25^{\circ} \mathrm{C}$, embaladas a vácuo. Durante o período de permanência das paletas dentro da câmara e durante o armazenamento, foram monitorados os valores de nitrito e TBARS com o objetivo de identificar onde o nitrito atuaria como conservante e antioxidante e onde o nível de TBARS poderia ser prejudicial à saúde do consumidor. Observou-se que a concentração dos nitritos até o décimo dia de permanência da paleta dentro da câmara, no segundo tratamento, atuou como efeito conservante tanto em superfície como em profundidade. Em relação ao efeito antioxidante, este esteve presente até o vigésimo dia no tratamento dois tanto em superfície como em profundidade. Os valores de TBARS encontrados na parte interna do produto em ambos os tratamentos após a saída da câmara e durante o período de armazenamento não provocariam danos à saúde do consumidor.

Palavras-chave: nitrito, TBARS, paleta suína, saúde, maturada, antioxidante.

\section{ABSTRACT}

Deboned swine palettes of $1.6 \mathrm{~kg}$ were submitted to injection of brine containing Staphylococcus xylosus. The palettes were maintained in a chamber with temperature control for 30 days at two different temperature ranges $\left(2^{\circ} \mathrm{C}\right.$ to $8^{\circ} \mathrm{C}$ and $4^{\circ} \mathrm{C}$ to $9^{\circ} \mathrm{C}$ ), were then stored for 120 days at $10^{\circ} \mathrm{C}$ and $25^{\circ} \mathrm{C}$ and vacuum packed. During maturation and storage, nitrite and TBARS were monitored, aiming to identify if nitrite would act as conserving and anti-oxidant agent and when the TBARS level would be harmful to consumer's health. The concentration of nitrite up to the $10^{\text {th }}$ day had a conserving effect in the surface and inside the palettes. The nitrite acted as anti-oxidant up to the $20^{\text {th }}$ day of the second treatment, also at the surface and inside the palettes. The TBARS content found inside the product for both treatments, after the maturation and storage period, would not be harmful for consumers.

Key words: nitrite, TBARS, swine palette, health, maturation, anti-oxidant.

\section{INTRODUÇÃO}

A concentração de nitrito presente num produto cárneo obtido por salga a seco e por desidratação pode agir como um obstáculo ("Hurdle Technology”) frente às fontes de alterações desse tipo de produto (LÜCKE, 1994; HAGEN et al., 1996; HUGAS, 1997; ARNAU et al., 1998; MARTÍN, 1998). Por outro lado, o conhecimento do valor de nitrito e de TBARS é importante, pois são considerados parâmetros físicoquímicos de qualidade em produtos cárneos maturados, fermentados e no presunto curado.

A concentração de nitrito necessária para ocorrência dos diversos efeitos quando de seu emprego em produtos cárneos varia entre 30 e 50ppm para o desenvolvimento de cor, entre 20 e 40ppm para

\footnotetext{
${ }^{1 *}$ Departamento de Ciência e Tecnologia de Alimentos, Centro de Ciências Rurais (CCR), Universidade Federal de Santa Maria (UFSM), Faixa de Camobi, Km9, Camobi, 97105-900, Santa Maria, RS. E-mail: nelcindo@terra.com.br.

${ }^{2}$ Curso de Engenharia de Alimentos, Universidade Regional Integrada (URI), Av. 7 de setembro, 1621, 99700-000, Erechim, RS, Brasil. ${ }^{3}$ Curso de Pós-graduação em Tecnologia de Alimentos da Universidade Federal do Paraná (UFPR), Centro Politécnico, Jardim das Américas, Usina Piloto, Bloco A, Sala PO17, Caixa Postal 19011, 81531-990, Curitiba, PR, Brasil.
} 
desenvolvimento de aroma, entre 80 e 150ppm para o efeito conservante (MÜLLER, 1991) e entre níveis de 20 e 50ppm para o efeito antioxidante (LÜCKE, 2000).

A oxidação dos lipídios é um dos problemas que causam as deteriorações no aroma e a diminuição na vida útil das carnes e dos produtos cárneos (WICK et al., 2001). Mais importante do que o teor lipídico de um alimento, é a forma na qual este se encontra e conseqüentemente sua possível participação em doenças crônicas ou degenerativas. O aldeído malônico e outros produtos da oxidação lipídica têm chamado a atenção da comunidade científica por sua provável relação com a formação de câncer. Valores de TBARS acima de 1,59mg de aldeído malônico / kg de amostra podem causar danos à saúde do consumidor (TORRES e OKANI, 2000).

O objetivo deste trabalho foi monitorar os valores de nitrito e TBARS durante o processamento e armazenamento da paleta suína curada, maturada e fermentada, para identificar onde o nitrito atuaria como conservante e antioxidante e onde o nível de TBARS poderia ser prejudicial à saúde do consumidor.

\section{MATERIAL E MÉTODOS}

Dez peças de paleta suína sem pele e camada de gordura, apresentando cada uma peso médio de 1,6 $( \pm 0,2) \mathrm{kg}, 20( \pm 5) \mathrm{cm}$ de largura, $25( \pm 6) \mathrm{cm}$ de comprimento e $8( \pm 2) \mathrm{cm}$ de espessura, foram submetidas à injeção de salmoura constituída por $25 \%$ de $\mathrm{NaCl}, 1,25 \%$ de sais de cura, 1,12\% de eritorbato de sódio e $72,63 \%$ de água, sendo preparada 18 horas antes do uso e armazenada a $5^{\circ} \mathrm{C}$. A cultura iniciadora de Staphylocccus xylosus foi hidratada em água não clorada, à temperatura de $15^{\circ} \mathrm{C}$, durante 30 minutos. A quantidade de cultura adicionada foi de 4,5g em $36 \mathrm{ml}$ de água (conforme orientação do fornecedor), sendo depois misturada com a salmoura. A proporção de ,salmoura injetada nas peças foi de $20 \%$ (v/p) e, em seguida as peças foram colocadas no "Tambler" a vácuo, onde permaneceram durante uma hora (30 minutos em movimento a 32 rpm e 30 minutos parados). Decorrido o tempo, foram levadas à câmara de maturação, onde permaneceram trinta dias, em duas faixas de temperaturas diferentes $\left(2^{\circ} \mathrm{C}\right.$ a $8^{\circ} \mathrm{C}$ e de $4^{\circ} \mathrm{C}$ a $9^{\circ} \mathrm{C}$ ), em que cada uma correspondeu a um tratamento.

No primeiro tratamento, a temperatura dentro da câmara variou de $2^{\circ}$ a $8^{\circ} \mathrm{C}$ e a umidade relativa, de $45 \%$ a $25 \%$. Passado os trinta dias dentro câmara (ponto de coleta de amostra de 1 ao 6), as paletas foram embaladas a vácuo em sacos plásticos coextrudadonylon poli-cinco camadas com espessura de $100 \mu \mathrm{e}$ armazenadas $\mathrm{a}+25^{\circ} \mathrm{C}( \pm 2)$, durante 120 dias (ponto de coleta de amostra de 7 ao 10).
No segundo tratamento, a temperatura dentro da câmara variou de $4^{\circ}$ a $9^{\circ} \mathrm{C}$ e a umidade relativa, de $55 \%$ a $45 \%$, e as paletas foram armazenadas à temperatura de $10^{\circ} \mathrm{C}( \pm 2)$ durante 120 dias. Tempo de permanência das paletas dentro da câmara, tipo de embalagem, tipo de fechamento, e tempo de armazenamento do primeiro tratamento, ocorrendo modificação em relação à temperatura e à umidade relativa dentro da câmara, e da temperatura de armazenamento, que foi $10^{\circ} \mathrm{C}$.

As amostras para determinação dos valores de nitrito e TBARS foram coletadas durante a etapa de processamento da paleta (ponto de coleta de 1 ao 6), e a cada 30 dias, durante os 120 dias de armazenamento (ponto de coleta de 7 ao 10). As análises foram efetuadas com três repetições, retirando-se amostras na superfície (espessura de $2 \mathrm{~mm}$ ) e em profundidade (no centro).

As temperaturas empregadas na câmara de maturação e durante o armazenamento nos dois tratamentos tiveram como base estudo bibliográfico efetuado sobre o presunto curado espanhol. As análises efetuadas em superfície e profundidade foram realizadas com objetivo de avaliar o comportamento em diferentes pontos do mesmo produto os quesitos monitorados.

Os pontos de coletas das análises foram divididos da seguinte maneira: 1) matéria-prima; 2) após injeção da salmoura e tamblemaneto; 3) após 2 dias dentro da câmara de maturação; 4) após 10 dias dentro da câmara; 5) após 20 dias dentro da câmara; 6) após 30 dias dentro da câmara; 7) após 30 dias de armazenamento; 8) após 60 dias de armazenamento; 9) após 90 dias de armazenamento e ponto de coleta 10) após 120 dias de armazenamento.

Análises físico-químicas

Nitritos

O teor de nitrito das amostras foi determinado segundo metodologia descrita pelo IAL (1985).

TBARS

A oxidação lipídica foi monitorada pela medida do número de TBARS, de acordo com a técnica de TARLADGIS (1964) modificada por CRACKER et al. (1988), seguindo as recomendação de SHAHID et al. (1985) no que se refere à adição de sulfanilamida para amostras que contêm nitrito, e por teste de recuperação, conforme descrito em TORRES et al. (1989). Essa técnica foi adaptada para o laboratório de Bioquímica de Alimentos por teste / Universidade Regional Integrada do Alto Uruguai e das Missões (URI-Campus de Erechim-RS). 
Análises estatísticas

Os resultados obtidos na superfície em profundidade da paleta, em cada tratamento e em cada ponto de coleta, foram analisados estatisticamente através de cálculos de média, desvio padrão, análise de variância e teste de Tukey com significância ao nível de $5 \%$, para ver se ocorreria diferença significativa entre eles ( $\mathrm{P}<0,05)$. (CAMPOS, 1983).

\section{RESULTADOS E DISCUSSÃO}

Nitrito

Na superfície das peças do primeiro tratamento, a concentração variou de 78,75ppm a 0,99ppm, enquanto que, em profundidade, foi de 175,11ppm a 1,00ppm (Tabela 1). Para o segundo tratamento, a variação em superfície foi de 134,61ppm a 4,61ppm e, em profundidade, de 180,73ppm a 6,31ppm (Tabela 1). Quando comparamos os tratamentos, observa-se que, na superfície do segundo tratamento, os pontos de coletas de amostras 2, 3, 4, 5, 7, 8, 9 e 10 apresentaram concentrações mais elevadas de nitritos e também foram significativas $(\mathrm{P}<0,05)$ essas diferenças. No interior das peças, também foram os mesmos pontos de coletas que apresentaram maiores concentrações no segundo tratamento, mas o ponto de coleta de amostra 3 não apresentou diferença significativa $(\mathrm{P}<0,05)$.

O valor máximo permitido de nitrito em presunto curado chinês, no final do processamento, é de 20ppm, conforme ZHU (1998), e pela legislação brasileira, é de no máximo 150ppm de produto (ABIA,1998). Em ambos os tratamentos, no final do processamento da paleta (ponto de coleta de amostra 6) e durante todo período de armazenamento, os valores de nitritos determinados foram menores tanto em superfície como em profundidade, quando comparados aos valores máximos permitidos no presunto chinês e para a legislação brasileira (Tabela 1 ).

As concentrações de nitrito necessárias para ocorrência dos diversos efeitos nos produtos cárneos seriam de 30 a 50ppm para desenvolvimento de cor; de 20 a 40ppm para desenvolvimento de aroma, de 80 a 150ppm para o efeito conservante (MÜLLER, 1991), e entre 20 a 50ppm para o efeito antioxidante, sendo que esses valores dependem do tipo de produto cárneo (LÜCKE, 2000). Em ambos os tratamentos, tanto na superfície como no interior da peça, as concentrações de nitrito permitem o desenvolvimento dos quatro efeitos (cor, aroma, conservante e antioxidante) somente nos pontos de coleta de amostra 2 e 3 (Tabela 1). No ponto de coleta da amostra 4 de ambos os tratamentos, também em superfície e profundidade. Além disso e mais no ponto de coleta no amostra 5 em profundidade, do segundo tratamento, teríamos três dos efeitos (cor, aroma e antioxidante). Ainda no ponto de coleta de amostra 5, mas em profundidade no primeiro tratamento e na superfície do segundo, teríamos apenas dois efeitos (aroma e antioxidante). Chama a atenção que após a coleta de amostra 3, o efeito conservante desaparece, mas, pela teoria dos obstáculos (LEISTNER, et al., 1994), as baixas temperaturas empregadas durante a fase de processamento nos dois tratamentos $\left(2^{\circ}\right.$ a $\left.4^{\circ} \mathrm{C}\right)$, somadas aos valores de atividade de água apresentados: 0,969 (superfície) e 0,966 (profundidade),

Tabela 1 - Valores de nitrito encontrados nos pontos de coleta de amostra durante a etapa de processamento e armazenamento da paleta no primeiro e no segundo tratamentos.

\begin{tabular}{|c|c|c|c|c|c|c|c|c|c|}
\hline M-Prima & Ponto 2 & Ponto 3 & Ponto 4 & Ponto 5 & Ponto 6 & Ponto 7 & Ponto 8 & Ponto 9 & Ponto 10 \\
\hline Zero dia & Zero dia & $2^{\circ}$ dia & $10^{\circ}$ dia & $20^{\circ}$ dia & $30^{\circ}$ dia & ${ }^{1} 60^{\circ}$ dia & $90^{\circ}$ dia & $120^{\circ}$ dia & $150^{\circ}$ dia \\
\hline \multirow{2}{*}{$S^{*}$ ND } & $78,75^{d}$ & $86,98^{c}$ & $38,08^{\mathrm{c}}$ & $14,41^{\mathrm{d}}$ & $5,97^{\mathrm{bc}}$ & $4,94^{\mathrm{b}}$ & $0,99^{c}$ & $2,60^{c}$ & $1,97^{\mathrm{b}}$ \\
\hline & $( \pm 1,02)$ & $( \pm 1,53)$ & $( \pm 2,68)$ & $( \pm 1,26)$ & $( \pm 0,99)$ & $( \pm 0,05)$ & $( \pm 0,00)$ & $( \pm 0,57)$ & $( \pm 0,04)$ \\
\hline \multirow{2}{*}{ P\# ND } & $89,09^{c}$ & $175,11^{\mathrm{a}}$ & $48,23^{b}$ & $20,34^{\mathrm{c}}$ & $13,37^{\mathrm{a}}$ & $4,77^{\mathrm{b}}$ & $1,00^{c}$ & $2,98^{\mathrm{c}}$ & $1,96^{\mathrm{b}}$ \\
\hline & $( \pm 0,47)$ & $( \pm 1,74)$ & $( \pm 0,61)$ & $( \pm 1,41)$ & $( \pm 0,35)$ & $( \pm 0,10)$ & $( \pm 0,00)$ & $( \pm 0,01)$ & $( \pm 0,02)$ \\
\hline \multirow{2}{*}{$S^{\omega}$ ND } & $134,61^{\mathrm{a}}$ & $111,96^{\mathrm{b}}$ & $61,18^{\mathrm{a}}$ & $25,65^{\mathrm{b}}$ & $4,61^{\mathrm{c}}$ & $11,38^{\mathrm{a}}$ & $7,58^{\mathrm{b}}$ & $4,85^{\mathrm{b}}$ & $7,27^{\mathrm{a}}$ \\
\hline & $( \pm 5,55)$ & $( \pm 1,41)$ & $( \pm 5,26)$ & $( \pm 1,13)$ & $( \pm 1,11)$ & $( \pm 1,57)$ & $( \pm 1,12)$ & $( \pm 0,08)$ & $( \pm 0,59)$ \\
\hline \multirow{2}{*}{$\mathrm{P}^{\phi} \mathrm{ND}$} & $110,67^{\mathrm{b}}$ & $180,73^{\mathrm{a}}$ & $57,74^{\mathrm{a}}$ & $66,58^{\mathrm{a}}$ & $7,39^{\mathrm{b}}$ & $13,43^{\mathrm{a}}$ & $14,98^{\mathrm{a}}$ & $6,56^{\mathrm{a}}$ & $6,31^{\mathrm{a}}$ \\
\hline & $( \pm 2,96)$ & $( \pm 7,53)$ & $( \pm 0,37)$ & $( \pm 2,88)$ & $(0,67)$ & $( \pm 1,80)$ & $( \pm 1,14)$ & $( \pm 0,62)$ & $( \pm 0,56)$ \\
\hline
\end{tabular}

NOTA: $\mathrm{S}^{*}$ : superfície; P\#: profundidade do $1^{\circ}$ tratamento. $\mathrm{S}^{\omega}$ : superfície; $\mathrm{P}^{\phi}$ : profundidade do $2^{\circ}$ tratamento. ND: não determinado. ${ }^{1}$ Dias contados desde o início do processamento. Resultados expressos em ppm e o desvio padrão encontram-se entre parênteses. No $1^{\circ}$ tratamento, a temperatura variou de $2^{\circ}$ a $8^{\circ} \mathrm{C}$ e a umidade, de $25 \%$ a $45 \%$ na câmara, e o armazenamento foi a $25^{\circ} \mathrm{C}( \pm 2)$. No $2^{\circ}$ tratamento, a temperatura variou de $4^{\circ}$ a $9^{\circ} \mathrm{C}$ e a umidade, de $45 \%$ a $55 \%$ na câmara, e o armazenamento foi a $10^{\circ} \mathrm{C}\left( \pm 2^{\circ} \mathrm{C}\right.$ ). a,b,c,d são analisadas na vertical. Letras diferentes apresentam diferença significativa $(\mathrm{P}<0,05)$. 
no primeiro tratamento, e 0,958 (superfície) e 0,956 (profundidade) no segundo, agiriam como barreiras frente ao desenvolvimento de microrganismos patogênicos (CARRASCOSA \& CORNEJO, 1989).

Em produtos cárneos fermentados, a passagem de nitrito para ácido nitroso e para óxido nitroso é devida à ação da enzima nitrito redutase, que está presente em representantes da família Micrococcaceae, sendo rápida essa reação em $\mathrm{pH}$ inferior a 5,6 e lenta em pH maior que 6,2 (ARNAU et al., 1998; TERRA, 1998). Para a enzima nitrito redutase agir como agente redutor à contagem da família Micrococcaceae, deve estar próxima a $10^{6} \mathrm{UFC} \mathrm{g}^{-1}$ (CAMPBELL-PLATT \& COOK, 1995). Na paleta suína, durante as etapas de processamento e armazenamento, a redução nos níveis de nitrito em ambos os tratamentos ocorreu pela ação da enzima nitrito redutase presente nos representantes da família Micrococcaceae, sendo mais acentuada a partir do ponto de coleta de amostra 4, em decorrência das contagens da família estarem próximas a $10^{6} \mathrm{UFC} \mathrm{g}^{-1}$ (dados não mostrados). Alguns pontos de coleta de amostras chamaram a atenção como os pontos 4, 5 e 7, pertencentes ao primeiro tratamento, e 4, 6 e 9, do segundo, tanto em superfície quanto em profundidade. Nesses pontos de coletas de amostras, os valores de $\mathrm{pH}$ foram menores do que 6,0 (dados não mostrados), estando próximos ao $\mathrm{pH}$ ideal de ação da enzima, os quais, somados às contagens da família
Micrococcaceae, que se encontrava em $10^{6} \mathrm{UFC} / \mathrm{g}$, promoveram uma rápida redução na quantidade dos nitritos (Tabela 1).

\section{TBARS}

Na tabela 2, encontram-se os valores de TBARS expressos em mg de malonaldeído por kg de amostra. Nela observa-se que os valores em profundidade no primeiro tratamento variaram de $0,025 \mathrm{mg}$ a $0,171 \mathrm{mg}$, e no segundo, de $0,016 \mathrm{mg}$ a $0,579 \mathrm{mg}$. Na superfície, a variação foi de $0,025 \mathrm{mg}$ a $3,173 \mathrm{mg}$ no primeiro e de $0,020 \mathrm{mg}$ a $2,383 \mathrm{mg}$ no segundo tratamento. Nos pontos de coleta de amostras 6 e 8, em superfície, do primeiro tratamento, e nos pontos de coleta de amostras 6, 7 e 10 do segundo, as amostras apresentavam uma camada de gordura de 1 a $2 \mathrm{~mm}$.

O trabalho de TORRES \& OKANI (2000) apresentou os valores de TBARS por grupo de alimentos. No grupo das carnes, o valor variou de 0,20 a 1,25mg de aldeído malônico / kg de amostra, e, no grupo dos pescados, de 0,215 a 3,32mg. No primeiro tratamento em superfície, os pontos de coleta de amostras 1, 2, 3, 4, 5 e 9 apresentaram valores iguais ou inferiores a 0,20mg de aldeído malônico/ kg de amostra, e os pontos de coleta 7 e 10 ficaram dentro da faixa compreendida para o grupo das carnes (Tabela 2). Já em profundidade, todos os resultados ficaram abaixo

Tabela 2 - Valores de TBARS encontrados nos pontos de coleta de amostra durante a etapa de processamento e armazenamento da paleta no primeiro e no segundo tratamentos.

\begin{tabular}{|c|c|c|c|c|c|c|c|c|c|}
\hline M-Prima & Ponto 2 & Ponto 3 & Ponto 4 & Ponto 5 & Ponto 6 & Ponto 7 & Ponto 8 & Ponto 9 & Ponto10 \\
\hline Zero dia & Zero dia & $2^{\circ}$ dia & $10^{\circ}$ dia & $20^{\circ}$ dia & $30^{\circ}$ dia & ${ }^{1} 60^{\circ}$ dia & $90^{\circ}$ dia & $120^{\circ} \mathrm{dia}$ & $150^{\circ} \mathrm{dia}$ \\
\hline $\begin{array}{l}S^{*} \\
0,025^{a} \\
( \pm 0,006)\end{array}$ & $\begin{array}{l}0,038^{\mathrm{a}} \\
( \pm 0,021)\end{array}$ & $\begin{array}{l}0,076^{\mathrm{ab}} \\
( \pm 0,021)\end{array}$ & $\begin{array}{l}0,118^{\mathrm{ab}} \\
( \pm 0,057)\end{array}$ & $\begin{array}{l}0,198^{\mathrm{a}} \\
( \pm 0,095)\end{array}$ & $\begin{array}{l}3,015^{\mathrm{a}} \\
( \pm 0,383)\end{array}$ & $\begin{array}{l}0,485^{\mathrm{b}} \\
( \pm 0,031)\end{array}$ & $\begin{array}{l}3,173^{\mathrm{a}} \\
( \pm 0,195)\end{array}$ & $\begin{array}{l}0,175^{\mathrm{a}} \\
( \pm 0,038)\end{array}$ & $\begin{array}{l}0,220^{\mathrm{b}} \\
( \pm 0,057)\end{array}$ \\
\hline $\mathrm{P} \#$ & & & & & & & & & $0,134^{\mathrm{bc}}$ \\
\hline $\begin{array}{l}0,025^{\mathrm{a}} \\
( \pm 0,006)\end{array}$ & $\begin{array}{l}0,017^{\mathrm{a}} \\
( \pm 0,004)\end{array}$ & $\begin{array}{l}0,019^{b} \\
( \pm 0,006)\end{array}$ & $\begin{array}{l}0,033^{\mathrm{b}} \\
( \pm 0,004)\end{array}$ & $\begin{array}{l}0,014^{\mathrm{b}} \\
( \pm 0,009)\end{array}$ & $\begin{array}{l}0,082^{\mathrm{c}} \\
( \pm 0,006)\end{array}$ & $\begin{array}{l}0,150^{\mathrm{b}} \\
( \pm 0,009)\end{array}$ & $\begin{array}{l}0,171^{\mathrm{b}} \\
( \pm 0,017)\end{array}$ & $\begin{array}{l}0,084^{\mathrm{a}} \\
( \pm 0,016)\end{array}$ & $( \pm 0,043)$ \\
\hline $\begin{array}{l}S^{\omega} \\
0,029^{a} \\
( \pm 0,003)\end{array}$ & $\begin{array}{l}0,020^{\mathrm{a}} \\
( \pm 0,004)\end{array}$ & $\begin{array}{l}0,111^{\mathrm{a}} \\
( \pm 0,025)\end{array}$ & $\begin{array}{l}0,200^{\mathrm{a}} \\
( \pm 0,037)\end{array}$ & $\begin{array}{l}0,181^{\mathrm{a}} \\
( \pm 0,034)\end{array}$ & $\begin{array}{l}1,893^{\mathrm{b}} \\
( \pm 0,168)\end{array}$ & $\begin{array}{l}2,383^{\mathrm{a}} \\
( \pm 0,697)\end{array}$ & $\begin{array}{l}0,137^{\mathrm{b}} \\
( \pm 0,022)\end{array}$ & $\begin{array}{l}0,437^{\mathrm{a}} \\
( \pm 0,215)\end{array}$ & $\begin{array}{l}1,046^{\mathrm{a}} \\
( \pm 0,131)\end{array}$ \\
\hline $\begin{array}{l}\mathrm{P}^{\phi} \\
0,016^{\mathrm{a}} \\
( \pm 0,003)\end{array}$ & $\begin{array}{l}0,016^{\mathrm{a}} \\
( \pm 0,003)\end{array}$ & $\begin{array}{l}0,139^{\mathrm{a}} \\
( \pm 0,043)\end{array}$ & $\begin{array}{l}0,055^{\mathrm{b}} \\
( \pm 0,028)\end{array}$ & $\begin{array}{l}0,074^{\mathrm{ab}} \\
( \pm 0,019)\end{array}$ & $\begin{array}{l}0,054^{\mathrm{c}} \\
( \pm 0,007)\end{array}$ & $\begin{array}{l}0,240^{\mathrm{b}} \\
( \pm 0,036)\end{array}$ & $\begin{array}{l}0,031^{\mathrm{b}} \\
( \pm 0,016)\end{array}$ & $\begin{array}{l}0,579^{a} \\
( \pm 0,416)\end{array}$ & $\begin{array}{l}0,031^{\mathrm{c}} \\
( \pm 0,016)\end{array}$ \\
\hline
\end{tabular}

NOTA: $\mathrm{S}^{*}$ : superfície; P\#: profundidade do $1^{0}$ tratamento. $\mathrm{S}^{\omega}$ : superfície; $\mathrm{P}^{\phi}$ : profundidade do $2^{\circ}$ tratamento. ND: não determinado. ${ }^{1}$ Dias contados desde o início do processamento. Resultados expressos em mg de malonaldeído / kg de amostra e o desvio padrão encontra-se entre parênteses. No $1^{\circ}$ tratamento a temperatura variou de $2^{\circ}$ a $8^{\circ} \mathrm{C}$ e a umidade de $25 \%$ a $45 \%$ na câmara, e o armazenamento foi a $25^{\circ} \mathrm{C}( \pm 2)$. No $2^{\circ}$ tratamento, a temperatura variou de $4^{\circ}$ a $9^{\circ} \mathrm{C}$ e a umidade $45 \%$ a $55 \%$ na câmara, e o armazenamento foi a $10^{\circ} \mathrm{C}\left( \pm 2^{\circ} \mathrm{C}\right.$ ). a,b,c,d são analisadas na vertical. Letras diferentes apresentam diferença significativa $(\mathrm{P}<0,05)$. 
de $0,20 \mathrm{mg}$. No segundo tratamento os resultados que apresentaram valores abaixo de $0,20 \mathrm{mg}$ de aldeído malônico / kg de amostra foram os pontos de coleta 1, 2, 3, 5 e 8 em superfície e 1, 2, 3, 4, 5, 6, 8 e 10 em profundidade. Os pontos de coleta de amostra que apresentaram valores dentro da faixa de $0,20 \mathrm{mg}$ a $1,25 \mathrm{mg}$ foram 4,9 e 10, em superfície, e 7 e 9, em profundidade. Nos dois tratamentos, houve quatro pontos de coleta de amostras em superfície que apresentaram valores dentro da faixa do grupo de pescado $(0,215 \mathrm{mg}$ a $3,32 \mathrm{mg})$, que foram os pontos 6 e 8 , no primeiro tratamento, e 6 e 7 , no segundo. Esses altos valores nesses pontos de coletas de amostras são decorrentes da composição da gordura da paleta, que apresenta maior quantidade de ácidos graxos insaturados (UNIFESP, 2002), além da embalagem empregada não possuir uma alta barreira à luz e ao oxigênio.

Valores de TBARS de 1,240mg de aldeído malônico / kg de amostra forma obtidos por PINTO (1996), no final do processamento do “jerked beef” (que é o charque adicionado de nitrito e embalado a vácuo). Os valores obtidos em ambos os tratamentos no ponto de coleta de amostra 6 , em superfície, foram superiores, mas, em profundidade, foram inferiores. O teor de lipídios totais apresentado pela ponta de agulha, que é matéria-prima para o "jerked beef”, é de 19\% (UNIFESP, 2002), enquanto que o da paleta suína "in natura” (ponto de coleta 1) empregada neste trabalho foi de $1,87 \%$ e, no produto final, de 10,92\%. Embora a paleta apresente menor teor de lipídios em sua composição, há maior proporção de ácidos graxos polinsaturados (UNIFESP, 2002).

Os aromas de ranço em carnes são inicialmente detectados em valores de 0,5 a 2,0mg malonaldeído / kg de carne (O’NEILL et al.,1998). No primeiro tratamento, somente nos pontos de coleta $6 \mathrm{e}$ 8 em superfície poderia então ser detectado aroma de ranço. No segundo tratamento, ocorreria um maior número de pontos de coleta de amostra, que seriam os pontos 6, 7 e 10, em superfície, e o 9, em profundidade.

Valores de TBARS até 1,59mg de aldeído malônico / kg de amostra são considerados baixos para serem percebidos por análise sensorial e não causam alarme para a saúde do ser humano (TORRES \& OKANI, 2000). Na tabela 2, observa-se que, em superfície, os pontos de coleta 6 e 8 , do primeiro tratamento, e os pontos de coleta 6 e 7, do segundo, apresentaram valores acima de 1,59mg, podendo assim causar danos à saúde do consumidor.

\section{CONCLUSÕES}

O efeito conservante do nitrito nos dois tratamentos, tanto em superfície como em profundidade, esteve presente somente até o segundo dia de permanência das paletas dentro da câmara. Já o efeito antioxidante teve duração maior, pois foi até o décimo dia em superfície no primeiro tratamento e até o vigésimo dia no segundo tratamento. Em profundidade, para ambos os tratamentos, o efeito antioxidante esteve presente até o vigésimo dia.

Os valores de TBARS encontrados, em superfície, nos pontos de coleta 6 e 8 , no primeiro tratamento, e nos pontos de coleta 6 e 7, do segundo, causariam danos à saúde do consumidor.

\section{REFERÊNCIAS}

ABIA - Associação Brasileira das Indústrias da Alimentação. Portaria n. 1002. SVS de 11 de dezembro de 1998. Brasília, 3.176-3.188. 1998.

ARNAU, J. et al. The effect of green ham $\mathrm{pH}$ and $\mathrm{NaCl}$ concentration on cathepsin activities and the sensory characteristics of dry-cured Hams. Journal Science Food Agriculture, v.77, p.387-392, 1998.

CAMPBELL-PLATT, G.; COOK, P.E. 4. Bacterial fermentation of meats. Fermented Meats. London, UK: Chapman \& Hall, 1995. p.69-109.

CAMPOS, G.H. Estatística experimental não paramétrica. 4.ed. Piracicaba, São Paulo: ESALQ, 1983. 349p.

CARRASCOSA, A.V.; CORNEJO, I. Aspectos fisico-quimicos del curado de jamon serrano y su influencai sobre el desarrollo microbiano (Revisión). Aliementaria, p.27-33, 1989.

CRACKER, C.C. et al. Some further observation on the TBA test as index of lipid in meats. Journal Food Chemistry, p.187-196, 1988

HAGEN, B.F. et al. Bacterial proteinase reduces maturation time of dry fermented sausages. Journal of Food Science, v.61, n.5, p.1024-1029, 1996

HUGAS, M.; MONFORT, J.M. Bacterial starter cultures for meat fermetation. Food Chemistry, v.59, n.4, p.547-55, 1997.

IAL - Instituto Adolfo Lutz. Aditivos 5.3.4.3. Determinação espctrofotométrica de nitratos em alimentos após redução em coluna de cádmio. In: — Normas Analíticas. 3.ed. São Paulo, SP, 1985. Cap.5, p.96-98.

LEISTNER, L.; GORRIS, G.M.L. Food preservation by combined processes. Alemanha; FLAIR (Food Linked AgroIndustrial Research), 1994. 109p.

LÜCKE, F.K. Fermented meat products. Food Research International, v.27, p.299-307, 1994

LÜCKE, F.K. Use of nitrite and nitrate in the manufacture of meat products. Fleischwirtschaft International, v.4, p.3841, 2000.

MARTÍN, L. et al. Effects of salt and temperature on proteolysis during ripening of Iberian Ham. Meat Science, v.49, n.2, p.145-153, 1998. 
MÜLLER, W.D. Curing nas smoking: are they healthier processes today than used to be? Fleischwirtschaft, v.71, n.1, p.61-65, 1991.

O'NEILL, L.M. et al. Comparison of effects of dietary olive oil, tallow and vitamin $\mathrm{E}$ on the quality of broiler meat products. British Poultry Science, v.39, p.365-371, 1998.

PINTO, M.F. Culturas iniciadoras - Starters - no processamento de jerked beef, um derivado do charque 1996. 93f. Tese (Doutorado em Ciência de Alimentos) Faculdade de Ciências Farmacêuticas, Universidade de São Paulo.

SHAHIDI, E. et al. Effect of sulphanilamide on the TBA values of cured meats. Journal Food Science, Chigaco, v.50, p.274-275, 1985.

TARLADGIS, B.G. et al. Chemistry of the 2-tiobarbituric acid test for determination of oxidative rancity in foods. Journal Science Food Agricultury, Champaing, v.15, p.602-607, 1964

TERRA, N.N. Seção 3. Industrialização da carne. Apontamentos de tecnologia de carnes. São Leopoldo, RS: Unisinos, 1998. p.53.
TORRES, E.A.F.S. et al. Lipid oxidation in charqui (salted and dried beef). Food Chemistry, v.15, p.257-268, 1989.

TORRES, E.A.F.S.; OKANI, E.T. Teste de TBA - Ranço em alimentos. Trabalho original recebido do próprio autor. Universidade de São Paulo (USP) Faculdade de Saúde Pública Departamento de Nutrição. Av. Dr. Arnaldo, 715 USP/FSP/ HNT. 01246-904 São Paulo. eatorres@usp.br , 10 p. , ano 2000.

UNIFESP - Universidade Federal de São Paulo, Escola Paulista de Medicina. Base de Dados de Nutrientes do USDA. Acesso em: 01 de julho de 2002. On line. Disponível em: $<$ http://www.unifesp.br/ dis/servicos/nutri/nutri.php?id=2095; $=4666$ e $=2160>$

WICK, M. et al. Dietary supplementation of vitamin e affects the peroxide value of subcutaneous lamb fat. Journal of Muscle Foods, v.12, p.237-243, 2001.

ZHU, S. Dry-cured ham in China. El jamón curado: tecnología y análisis de consumo. In: SIMPÓSIO ESPECIAL, 44., ICoMST. 1998, Barcelona, Espanha. Anais... Barcelona, 1998. p.185188. 